Journal of Thermal Engineering, Vol. 6, No. 3, pp. 242-252, April, 2020

Yildiz Technical University Press, Istanbul, Turkey

\title{
EFFECTS OF THICKNESS AND CAMBER RATIO ON FLOW CHARACTERISTICS OVER AIRFOILS
}

\author{
İlyas Karasu1 ${ }^{1}$, Halil Hakan Açıkel ${ }^{1}$, Kemal Koca ${ }^{1, ~ *}$, Mustafa Serdar Genç${ }^{1}$
}

\begin{abstract}
This study ensures experimental and numerical investigation of different airfoils to observe and understand how camber ratio affects the flow characteristics over surface of different airfoils. Experimental results in the previous studies were used while the numerical study was performed for present investigation. Reynolds numbers based on the airfoil chords were $1 \times 10^{5}$ and the angle of attack of $8^{\circ}$. Instantaneous voltage output data were used in order to detect transition location for NACA 4412, oil surface visualization experiments were presented for NACA 2415. In the numerical analysis, values of $\mathrm{u} / \mathrm{U}_{\infty}$ and turbulent kinetic energy were presented for NACA 4415 airfoil. The experimental results denoted that the change of camber ratio and thickness significantly affected the flow phenomenon such as boundary layer separation or formation and progress of the laminar separation bubble. The long bubble was clearly observed with accumulation of pigments at oil-flow measurement experiment. By increasing the camber ratio with the use of NACA 4412 airfoil, the long bubble turned into the short bubble. Briefly, not only the progress and formation of laminar separation bubble was being affected, but also the onset of transition point was obviously influenced by changing of camber ratio.
\end{abstract}

Keywords: Camber Ratio, Thickness, Laminar Separation Bubble, Onset of Transition, Low Reynolds Number

\section{INTRODUCTION}

For over 75 years, there are many studies and investigations with regards to boundary layer transition over the surface of airfoil or wind turbine blade especially at operating low Reynolds number, but it still remains as a subject of research. According to the study presented by Arcara et al [1], fuel cost could be saved at $8 \%$ if delaying the transition phenomenon in boundary layer over the airfoil could be happened to $50 \%$. Boundary layer transition is, thus, an open field as a researchable topic. The statements like flow separation or laminar separation bubble (LSB) which affects the aerodynamic performance can be observed at boundary layer separation happening on the suction side of airfoil because of adverse pressure gradient (APG). In such circumstances, the flow's momentum becomes inadequate to cope with APG [2,3]. The flow adjacent to surface of airfoil, consequently, separates from the surface, as illustrated in Figure 1. Furthermore, the vortices shedding from leading-edge as well as trailing-edge of airfoil can be observed.

A private situation can be observed at transition region on surface of airfoil. The laminar separation exists and wall normal momentum on surface of airfoil can be changed. That momentum variation causes the separated flow to be reattached. As denoted at a schematic in Figure 2 lodged by Hu and Yang [4], the enclosed region limited by separation and reattachment point at fluid is named as LSB. The grade of both transition and separated region are characteristically larger at low Reynolds number cases.

Over the past decades, flow involving LSB was investigated by means of earlier studies carried out by Gaster [5] and Tani [6]. The studies as following research efforts were performed with regards to laminar to turbulent transition, which has been exhibited the key role to understand the characteristics and formation of LSBs in detail. Dovgal et al. [7] showed that the viscous effects were diminished when Reynolds number and the distance among wall and shear layer increased. As the study debated in detail by Diwan and Ramesh [8], the slow convective

This paper was recommended for publication in revised form by Ozgen Acikgoz

1 Wind Engineering and Aerodynamics Research Laboratory, Department of Energy Systems Engineering, Erciyes University, Kayseri, Turkey

${ }^{\star}$ E-mail address: kemalkoca@erciyes.edu.tr

Orcid id: 0000-0003-2464-6466

Manuscript Received 23 March 2018, Accepted 05 June 2018 
elaboration of disturbance owing to Tollmien-Schlichting instability can be signified as a natural vanguard to the major amplification occurred in LSB. The discussion based on the work of Brinkerhoff and Yaras [9], the later phases of transition phenomenon may also be impressed because of the small amplitude disturbances turning into LSB. LSB composed over the rectangular leading edge carried out by Cherry et al. [10] and the flow visualization in their study spilled the separate turbulent structures. Hain et al. [11] and McAuliffe and Yaras [12] clarified the formation of structures in the laminar separated flow and their importance in resurgence of turbulence around the airfoil for different angle of attacks by using Particle Image Velocimetry (PIV). LSB over an SD7003 airfoil was experimentally analyzed by Burgmann and Schröder [13] at low angle of attacks and Reynolds number ranging from $2 \times 10^{4}$ to $6 \times 10^{4}$. They examined that no steady formation statement was observed in zone of transitioning shear layer. Coherent structures composed in LSB passed the abrupt three-dimensional deformation. In terms of prediction of LSB, behavior of both turbulence and transition models were tested by Genç et al. [14-18] at low and high Reynolds number. They studied controlling of LSB by utilizing blowing and suction systems. Their study indicated that results of transition models correctly predicted progress of LSB, whilst results of turbulence models in terms of predicting flow phenomena in boundary layer showed changeable degrees of performance. Furthermore, LSB was extinguished in conjunction with use of blowing, suction and slat, revealing important results such as increasing of lift and decreasing of drag forces.

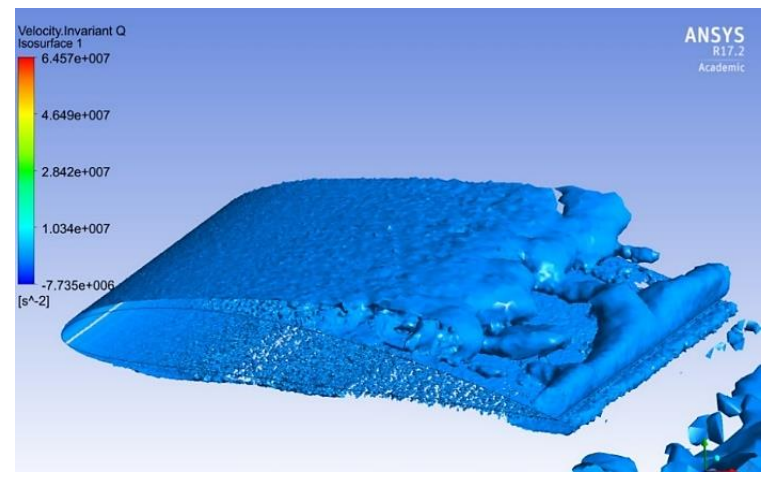

Figure 1. The visualization of boundary layer separation and vorticity around the airfoil.

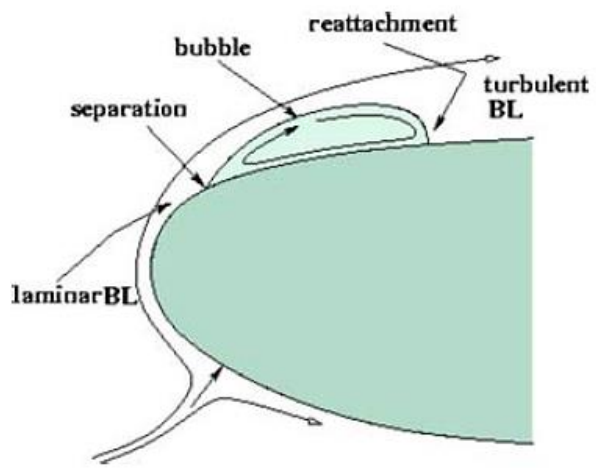

Figure 2. The schematic of laminar separation bubble [4].

A detailed analysis of blades for the flight vehicles is more crucial since the aerodynamic performance will be affected because of the presence of an unsteady loading such as different wind conditions [19]. These unsteady loads causing the instability over the airfoils can be suppressed or mitigated thanks to material of airfoil [20-22] or active-passive flow control techniques [23-26]. 
In terms of explaining aerodynamic phenomenon in accordance with thickness and camber variation, the objective of this study is to investigate the thickness and camber effects on aerodynamic performance of different airfoils. Thus, they were carried out and discussed with their results obtained from wind tunnel experiments and numerical study. Transition phenomenon as well as formation and characteristics of LSB, which was negative statement for aerodynamic performance of wind turbine airfoils, were investigated at Reynolds number of $1 \times 10^{5}$ and angle of attack of $8^{\circ}$. Novelty of this study was to identify the flow structures over suction surface of different airfoils and how thickness and camber ratio affected the aerodynamic characteristics of airfoils. Hence, it may potentially be pioneer study in terms of developing of wind turbine airfoils and contributing the desirable information to aerodynamic researchers interested in MAV and UAV designs.

\section{NUMERICAL METHOD}

\section{Computational Grid and Boundary Conditions}

For sufficient number of grid nodes, research of mesh independency was performed at $\mathrm{C}_{\mathrm{L}}$ graph of NACA 4415 airfoil as demonstrated in Figure 3. It was observed that $C_{L}$ value increased gradually from nodes number of $4.5 \times 10^{6}$ to $7.5 \times 10^{6}$, but there was no important variation between nodes number of $8 \times 10^{5}$ and $1 \times 10^{6}$ and $\mathrm{C}_{\mathrm{L}}$ curve was not affected significantly. Hence, number of grid nodes was composed about $1 \times 10^{6}$ in terms of reasonable results of NACA 4415 airfoil. Furthermore, computational grid was meshed in conjunction with structured tetrahedron grids. As computational domain, inlet and outlet were described as velocity inlet and pressure outlet, respectively. Other walls were defined as symmetry. As shown in computational domain in Figure 4, a second domain in C form was adopted to exactly imitate the flow above and wake of airfoil. In addition, inflation was utilized over the surface so that flow phenomena were investigated in detail. Height of first grid node was selected as $0.1 \mathrm{~mm}$ and aggregate boundary layer mesh deepness was $20 \mathrm{~mm}$. Enlargements and agent of mesh was 1.15 in boundary layer [27]. Hence, not only LSB and transition region over surface of airfoil were searched, but also effects of vortex shedding, which was caused by flow phenomena over surface, at the wake region were discussed. Regarding numerical model for this study, SST (Shear Stress Transport) transition model was utilized in terms of giving better solution for the LSB formation and transition onset. Air density was taken as $1.05 \mathrm{~kg} / \mathrm{m}^{3}$, which was used as same value for experiments.

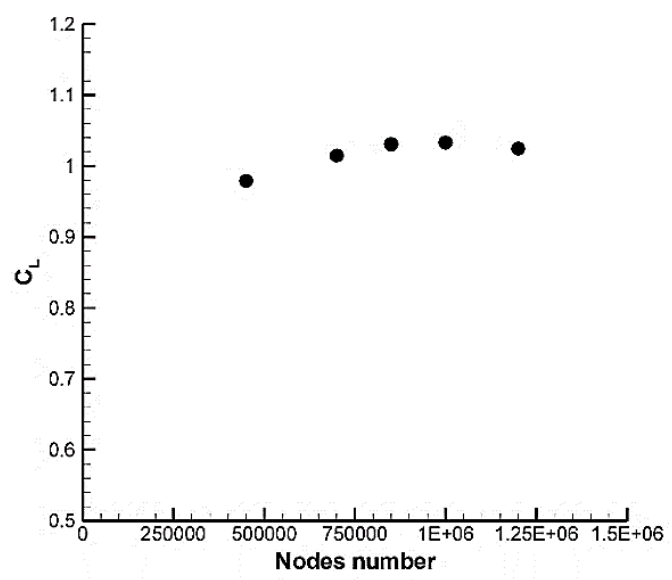

Figure 3. $C_{L}$ values obtained from numerical study of mesh independency for NACA 4415 airfoil, $\operatorname{Re}=1 \times 10^{5}, \alpha=8^{\circ}$ 


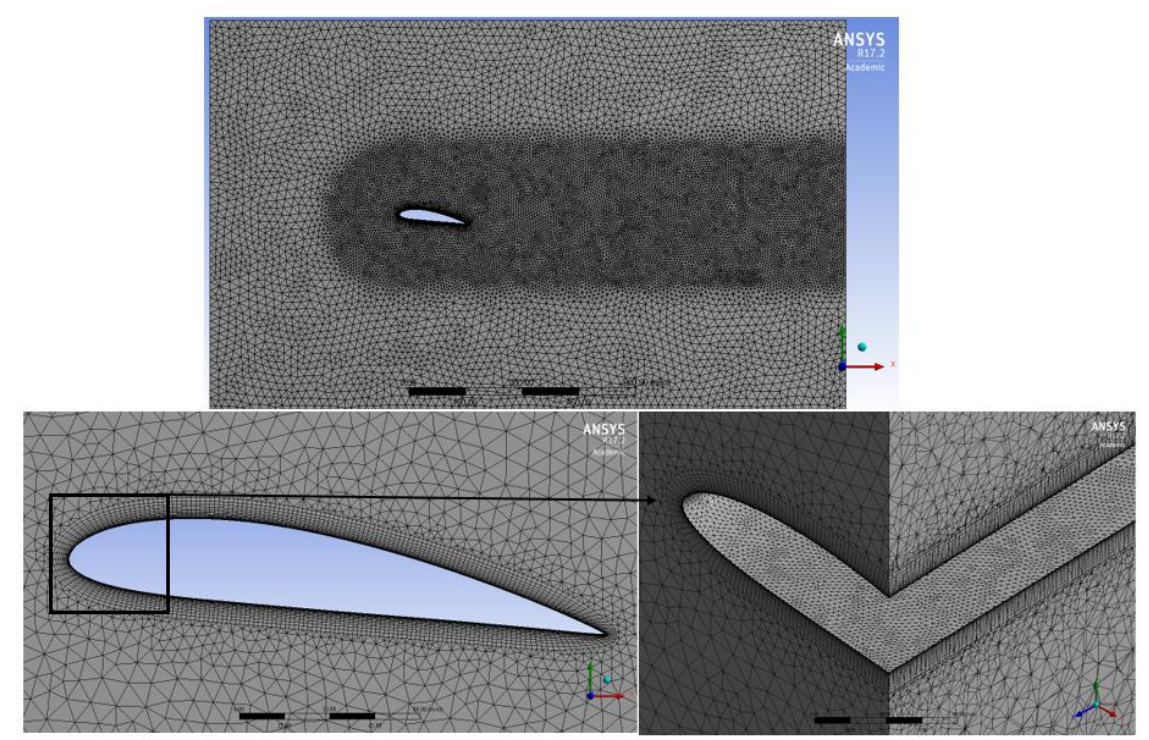

Figure 4. Mesh structures in local domain of NACA 4415 airfoil, $\operatorname{Re}=1 \times 10^{5}, \alpha=8^{\circ}$

\section{EXPERIMENTAL RIGS AND TEST SAMPLE}

\section{The Wind Tunnel, Test Sample and Experimental Apparatus}

Suction type and low speed wind tunnel was utilized for experiments. As illustrated from sketch of wind tunnel in Figure 5, it has square test chamber of $500 \mathrm{~mm}$ x $500 \mathrm{~mm}$. Maximum velocity of wind tunnel is $40 \mathrm{~m} / \mathrm{s}$. Moreover, turbulent intensity is about $0.7 \%$ for lowest velocity, whilst it is about $0.3 \%$ for highest velocity. NACA 4412 was chosen for experimental test model. It was produced by means of $3 \mathrm{D}$ printer $[28,29]$. In order to reduce surface roughness, surface was rubbed with a sandpaper. To prevent effect of tip-vortices, two plexiglass materials was utilized at each tip of airfoil as denoted in Figure 6. Measurement technique in conjunction with hot-film probes is proper for the discovery of the boundary layer transition [30,31]. However, the sum of heat transfers at hot-film's wire mounted over the surface of airfoil may unavoidably be affected by unwanted factors like flow characteristics and model substance [32]. The suitable calibration for hot-film probes are, hence, too complicated. To accomplish that puzzling statement and obtain the semi-measurable info about the condition of boundary layer, Hodson [33] and Zhang et al. [34] recognized the quasi wall-shear stress as followed:

$$
\tau=\left(\frac{E^{2}-E_{0}^{2}}{E_{0}^{2}}\right)^{3}
$$

where $\mathrm{E}$ indicates the voltage value coming from hot-film sensor and $\mathrm{E}_{0}$ indicates the voltage value at zero flow. In this study, the calibration procedure of hot-film probe was not enforced. Moreover, the hot-film sensor (type: glueon) with its usage code of 55R47 was performed by mounting on NACA 4412 airfoil as shown in Figure 7. It was installed over the surface of airfoil by using the double side type so as not to disturb the flow. Data was composed at chord (c) length of airfoil ranging from $0.1 \mathrm{c}$ to $0.8 \mathrm{c}$, respectively. 
Journal of Thermal Engineering, Research Paper, Vol. 6, No. 3, pp. 242-252, April, 2020

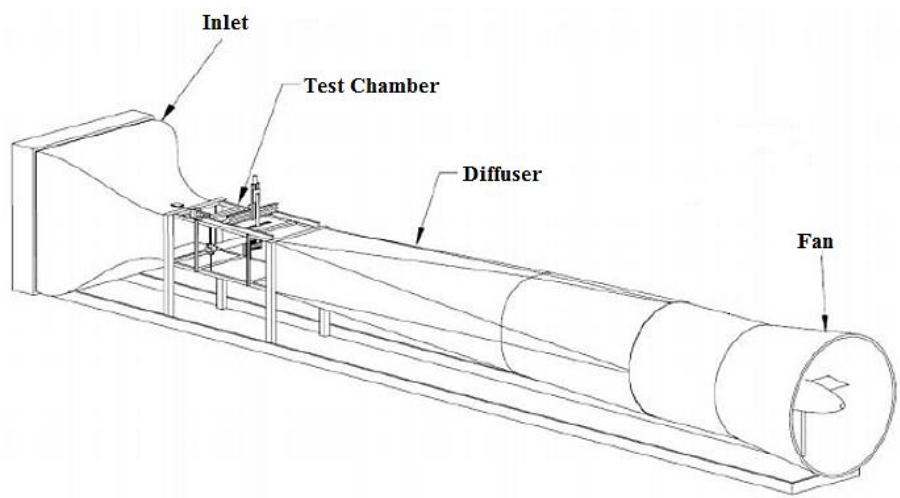

Figure 5. Sketch of the wind tunnel

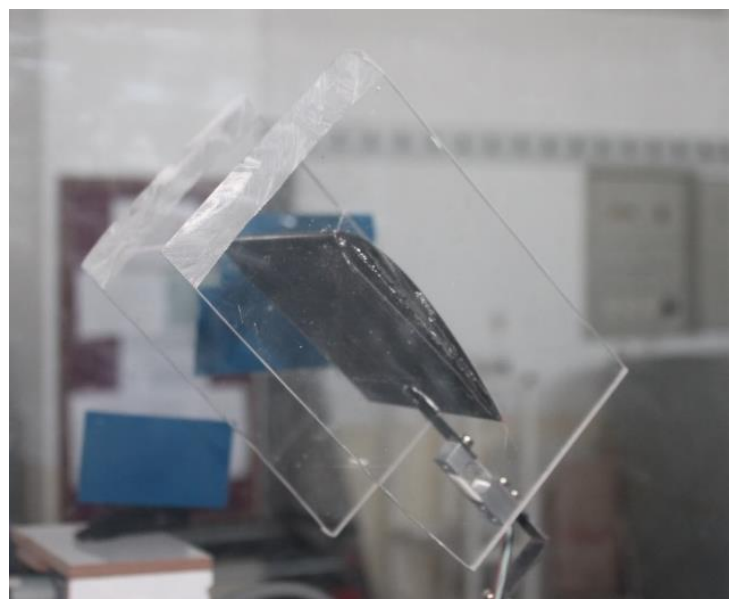

Figure 6. Experimental test model of NACA 4412 airfoil [29].

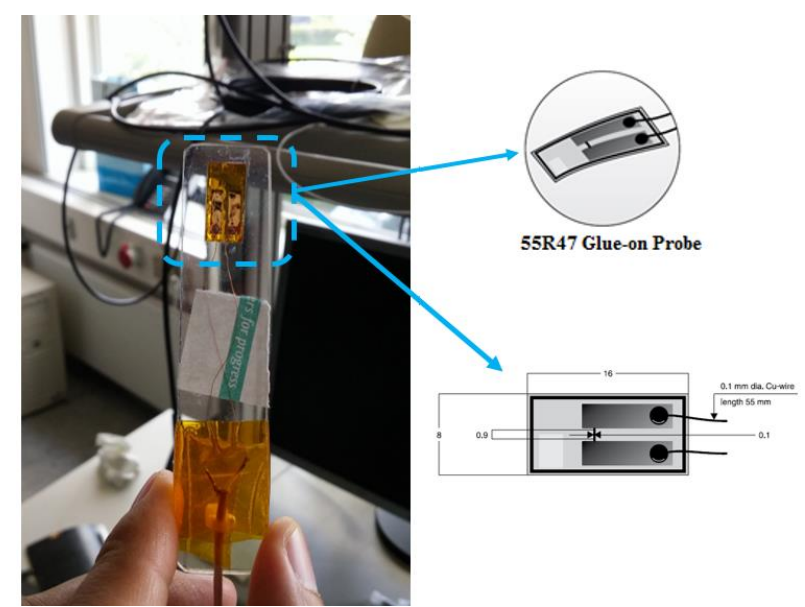

Figure 7. Hot-film probe [35]. 


\section{RESULTS}

\section{Numerical Analysis of Velocity and Vorticity}

In order to explain flow phenomena, numerical result of velocity analysis for NACA 4415 airfoil was shown in Figure 8. Flow over the suction surface of airfoil encountered in conjunction with adverse pressure gradients (APGs) and it separated from surface at $\mathrm{x} / \mathrm{c}=0.34$, since it did not have enough momentum to keep flow direction. After a while, separated flow reattached to surface at $\mathrm{x} / \mathrm{c}=0.46$. As illustrated in enlarged view, LSB occurs over suction surface. After LSB, APGs played a dominant role on flow and reverse flow area at the trailing-edge of airfoil expanded gradually. Thus, trailing-edge separation phenomenon was observed with completely separating flow.

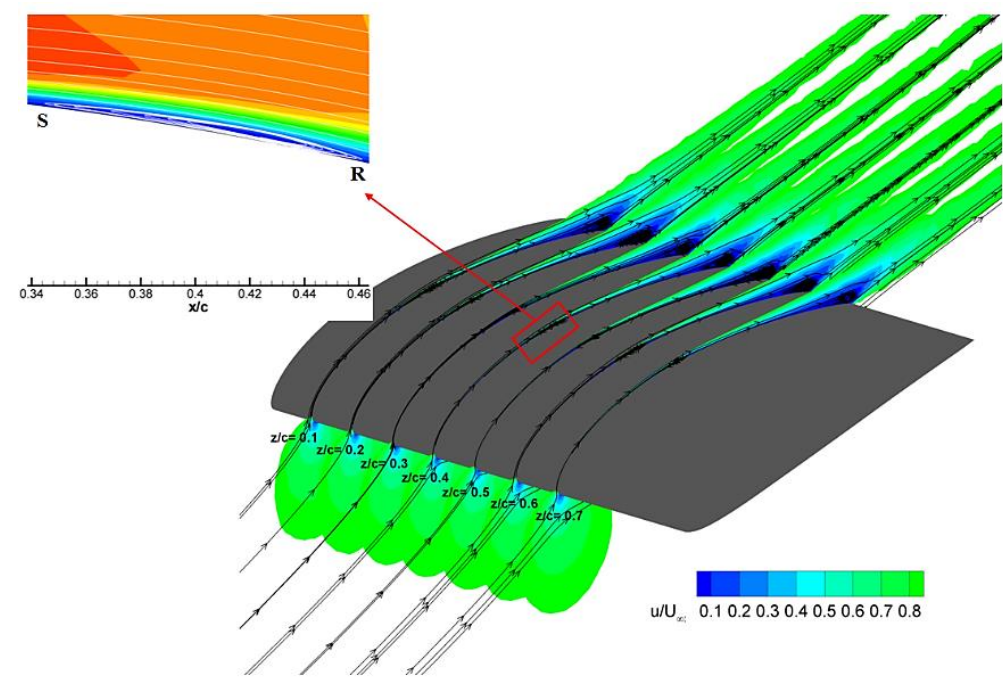

Figure 8. Numerical result of streamwise magnitude for NACA 4415 airfoil, $\operatorname{Re}=1 \times 10^{5}, \alpha=8^{\circ}$

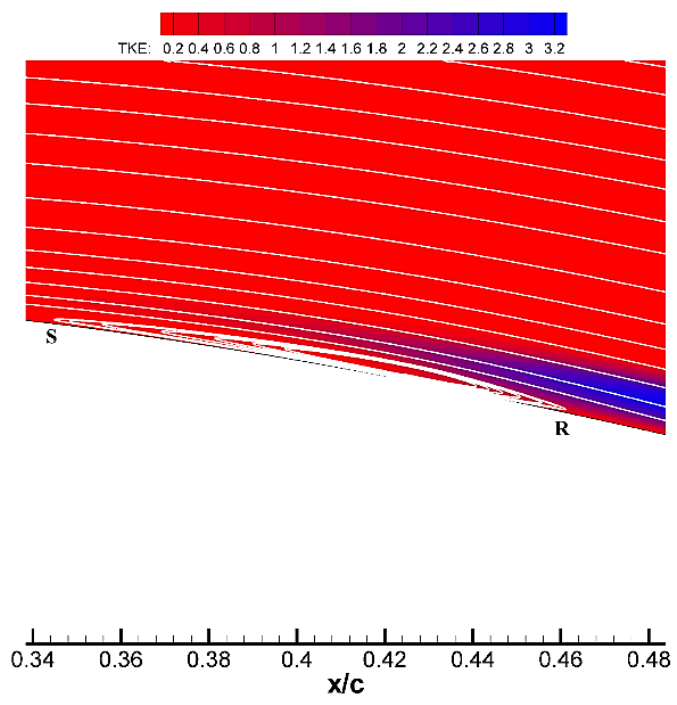

Figure 9. Turbulent kinetic energy distribution for NACA 4415 airfoil, $\mathrm{Re}=1 \times 10^{5}, \alpha=8^{\circ}$

Also, in terms of understanding of flow phenomena over suction surface of airfoil, turbulent statistics can play a key role in fluid mechanics. In Figure 9, LSB was revealed in bounded area where point of separation was at $\mathrm{x} / \mathrm{c}=0.34$ and point of reattachment was at $\mathrm{x} / \mathrm{c}=0.46$. Moreover, onset of transition point could be observed by planar contour and it was at $\mathrm{x} / \mathrm{c}=0.35$. In this point, undulations in boundary layer started to increase and flow was 
energized by means of these undulations. After a while, energized flow in boundary layer helped to overcome APGs after the transition to turbulence occurred at $\mathrm{x} / \mathrm{c}=0.45$ and the turbulent flow reattachment was observed at $\mathrm{x} / \mathrm{c}=$ 0.46. After that region, trailing-edge separation was occurred, because APGs were more dominant. Also, turbulent zone of NACA 4415 airfoil was denoted obviously. The flow in turbulent region was more chaotic. Moreover, vortices continued its way along vortex trajectory by increasing its size.

\section{Overview of Experimental Results and Comparison with Numerical Study}

In order to compare and understand how camber and thickness affected boundary layer phenomena, the experiments including hot-film probes at the NACA 4412 airfoil and oil-flow visualization at the NACA 2415 airfoil as well as numerical study for NACA 2415 were fulfilled at Reynolds number of $1 \times 10^{5}$ and the angle of attack of $8^{\circ}$. The voltages coming from the glue-on probe was simultaneously measured and it was showed at each $\mathrm{x} / \mathrm{c}$. As seen in Figure $10(\mathrm{a})$, the voltage at $\mathrm{x} / \mathrm{c}=0.3$ was 1.25 . It was read as 1.2 at $\mathrm{x} / \mathrm{c}=0.4$. It was pointed out that $0.4 \mathrm{c}$ of the airfoil was the onset of transition $\left(\mathrm{X}_{\mathrm{t}}\right)$. Additionally, it was estimated that there was a LSB at $\mathrm{x} / \mathrm{c}=0.4$, because the voltage value at $\mathrm{x} / \mathrm{c}=0.4$ was less than other $\mathrm{x} / \mathrm{c}$ 's values. Flow might be most probably in dead air region located at the aft of LSB. That is, it can be interpreted that the flow is nearly stagnant. However, undulations at $\mathrm{x} / \mathrm{c}=0.5$ and $\mathrm{x} / \mathrm{c}=0.6$ was more than the $\mathrm{x} / \mathrm{c}=0.4$. It was showed that the increase of undulations was caused by reverse flow vortices positioned at head of LSB. The undulations at $\mathrm{x} / \mathrm{c}=0.7$ and $\mathrm{x} / \mathrm{c}=0.8$ were also higher, but the voltage's value was less than the $\mathrm{x} / \mathrm{c}=0.6$. It can be said that the region at between $\mathrm{x} / \mathrm{c}=0.5$ and $\mathrm{x} / \mathrm{c}=0.8$ might be referred as turbulent region, because the flow was completely separated and voltage's values at this region increased because of shedding vortices having higher momentum at airfoil trailing-edge. Furthermore, it was obviously sighted that the transition length $\left(\mathrm{L}_{\mathrm{t}}\right)$ was $0.2 \mathrm{c}$ of airfoil. Despite semi-measurable information from hot-film sensor, it was useful to gain information in terms of the flow phenomena over the surface of airfoil.

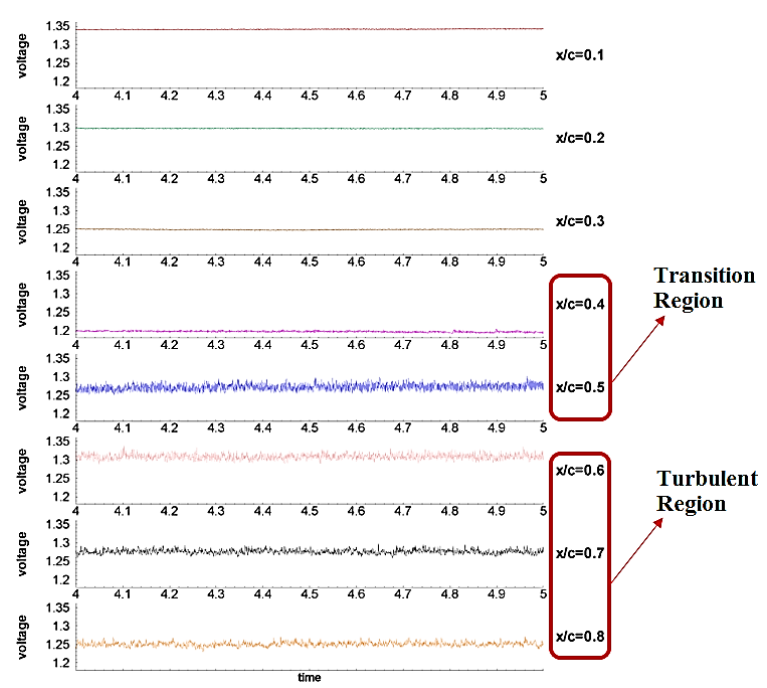

a)

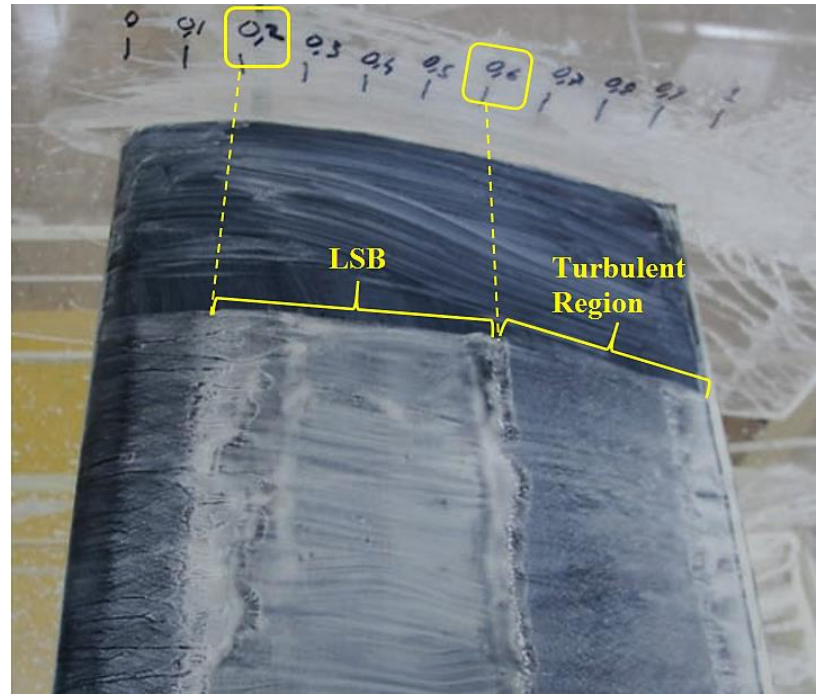

b)

Figure 10. a) Instantaneous voltage variance of hot-film sensor at NACA 4412 airfoil [28], b) Result of oil-flow visualization experiment over NACA 2415 airfoil $[36,37], \operatorname{Re}=1 \times 10^{5}, \alpha=8^{\circ}$

Besides, according to results of NACA 2415 airfoil as illustrated in Figure 10(b). The region where the flow separated at $\mathrm{x} / \mathrm{c}=0.2$ and reattached at $\mathrm{x} / \mathrm{c}=0.6$ over surface of airfoil was referred as LSB. In this case, the LSB can be classified as long bubble over the NACA 2415 airfoil. After $\mathrm{x} / \mathrm{c}=0.6$, reattached flow suddenly separated over surface and stall phenomenon, was occurred and a fully flow separation at trailing-edge was observed. This was because of the fact that the flow did not cope with APGs and the trailing-edge separation occurred after a while. This 
associated region was named as the turbulent region where the momentum of flow was higher than other part of airfoil.

Moreover, wall shear distribution at $\mathrm{x}$ direction of the NACA 4415 airfoil was showed in Figure 11. From the legend of wall shear stress distribution, dark blues under value of 0 (zero) stands for flow separation, whilst values above 0 (zero) indicates that flow continued to its way along chord-wise without flow separation. As seen the distribution, there was a LSB at limited area where presented by dark blue. As mentioned before, that limited area was between $\mathrm{x} / \mathrm{c}=0.34$ and $\mathrm{x} / \mathrm{c}=0.46$. After $\mathrm{LSB}$, the reattached flow was observed via the region presented by turquoise blue. $\mathrm{x} / \mathrm{c}=0.8$ point denoted by dark blue color stands for start point of trailing-edge separation. Flow characteristics in that region were turbulent and its level of energy was higher than other region. Figure 12 indicated results of turbulence statistics along chordwise of the NACA 4415 airfoil. After $\mathrm{x} / \mathrm{c}=0.3$, there was an abrupt increment at amount of turbulence gradually and plateau of graph was about $\mathrm{x} / \mathrm{c}=0.58$. It stands for that amount of momentum and kinetic energy in flow increased and turbulent flow occurred over suction surface of the NACA 4415 airfoil.

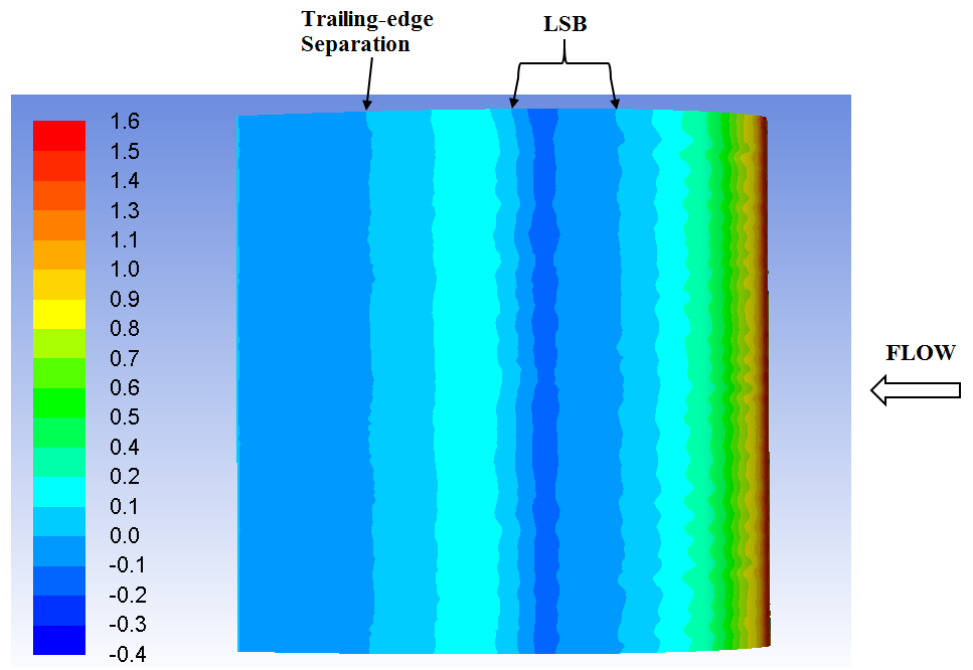

Figure 11. $X$ wall shear stress distribution at NACA 4415 airfoil, $\operatorname{Re}=1 \times 10^{5}, \alpha=8^{\circ}$

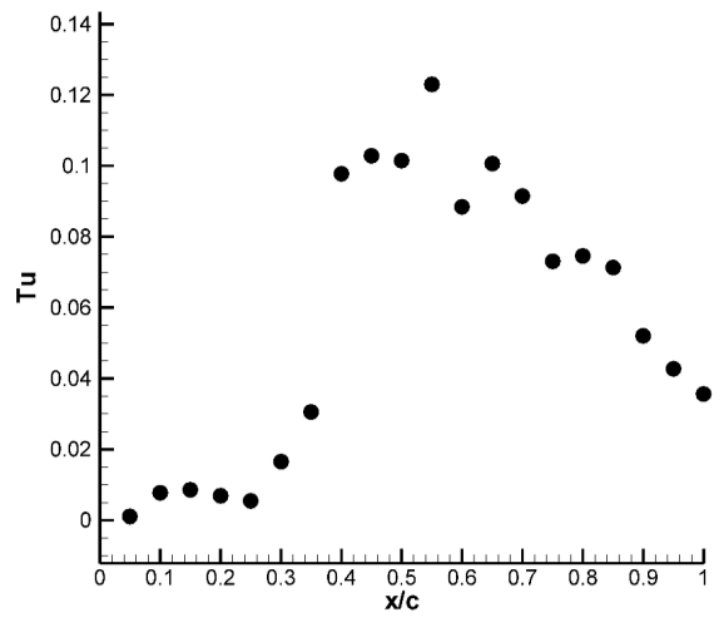

Figure 12. Turbulence intensity along chordwise of NACA 4415 airfoil, $\operatorname{Re}=1 \times 10^{5}, \alpha=8^{\circ}$

Briefly, both experimental and numerical results were shown in Table 1 . The flow over surface of the NACA 4412 airfoil separated at $\mathrm{x} / \mathrm{c}=0.3$ due to adverse pressure gradients and it reattached at $\mathrm{x} / \mathrm{c}=0.5$. The length of LSB was $0.2 \mathrm{c}$ on the NACA 4412 airfoil. Moreover, it was measured that transition onset was at $\mathrm{x} / \mathrm{c}=0.4$. In 
numerical results of the NACA 4415 airfoil, flow separation was observed at $\mathrm{x} / \mathrm{c}=0.34$ while point of reattachment was occurred at $\mathrm{x} / \mathrm{c}=0.46$. LSB, which affected the aerodynamic performance of airfoil negatively, was occurred in this region and its length measured as $0.12 \mathrm{c}$. Besides, onset of transition was observed at $\mathrm{x} / \mathrm{c}=0.35$ where its location was near the leading-edge of airfoil. Regarding the comparison of numerical results of NACA 4415 airfoil and experimental result of NACA 4412 airfoil, flow phenomena over the airfoils were affected with thickness increment of $25 \%$. The transition onset NACA 4412 airfoil was observed at $\mathrm{x} / \mathrm{c}=0.4$, while it was observed at $\mathrm{x} / \mathrm{c}=0.35$ for NACA 4415 airfoil. It means that transition onset moved towards up to $0.05 \mathrm{c}$. Moreover, it was concluded that LSB over suction surface of NACA 4412 was formed between $\mathrm{x} / \mathrm{c}=0.3$ and $\mathrm{x} / \mathrm{c}=0.5$, whilst it was occurred between $\mathrm{x} / \mathrm{c}=0.34$ and $\mathrm{x} / \mathrm{c}=0.46$ on NACA 4415 . It clearly pointed out that thickness increment at the airfoils caused the bubble length to reduce.

Table 1. Margins the transition $\left(\mathrm{X}_{\mathrm{t}}\right)$, the separation $\left(\mathrm{X}_{\mathrm{S}}\right)$, the reattachment $\left(\mathrm{X}_{\mathrm{r}}\right)$ points and laminar separation bubble length $\left(\mathrm{L}_{\mathrm{b}}\right)$ as $\mathrm{x} / \mathrm{c}$ acquired from both hot-film sensor and the oil-flow visualization experiments.

\begin{tabular}{|c|c|c|c|}
\hline & $\begin{array}{c}\text { NACA 2415 (Exp.) } \\
{[\mathbf{3 6 , 3 7 ]}}\end{array}$ & NACA 4415 (Num.) & $\begin{array}{c}\text { NACA 4412 (Exp.) } \\
{[28]}\end{array}$ \\
\hline Re number & $1 \times 10^{5}$ & $1 \times 10^{5}$ & $1 \times 10^{5}$ \\
\hline$\alpha\left(^{\circ}\right)$ & $8^{\circ}$ & $8^{\circ}$ & $8^{\circ}$ \\
\hline Chord length $(\mathrm{c})$ & $180 \mathrm{~mm}$ & $180 \mathrm{~mm}$ & $180 \mathrm{~mm}$ \\
\hline $\mathrm{X}_{\mathrm{t}}$ & 0.45 & 0.35 & 0.4 \\
\hline $\mathrm{X}_{\mathrm{s}}$ & 0.2 & 0.34 & 0.3 \\
\hline $\mathrm{X}_{\mathrm{r}}$ & 0.6 & 0.46 & 0.5 \\
\hline $\mathrm{L}_{\mathrm{b}}$ & 0.4 & 0.12 & 0.2 \\
\hline
\end{tabular}

On the other hand, in accordance with the experimental result of NACA 2415 airfoil and numerical result of NACA 4415 airfoil, increasing of camber ratio caused the flow characteristics to be changed over suction surfaces of airfoils. Onset of transition of NACA 4415 airfoil was occurred at $\mathrm{x} / \mathrm{c}=0.35$, whilst it was observed at $\mathrm{x} / \mathrm{c}=0.45$ on NACA 2415. Also, flow separated at $\mathrm{x} / \mathrm{c}=0.34$ and reattached at $\mathrm{x} / \mathrm{c}=0.46$ for NACA 4415. Yet, separation and reattachment points for NACA 2415 airfoil were observed at $\mathrm{x} / \mathrm{c}=0.2$ and $\mathrm{x} / \mathrm{c}=0.6$, respectively. It obviously concluded with increment of camber ratio that both transition onset was delayed by moving towards from $\mathrm{x} / \mathrm{c}=0.35$ to $\mathrm{x} / \mathrm{c}=0.45$, and the LSB length was decreased at $70 \%$.

Finally, with respect to two experimental results of airfoil (for both NACA 2415 and NACA 4412 airfoils), changing at both thickness and camber ratio of airfoils played a big role in terms of their aerodynamic performance. Because, point of flow separation for NACA 2415 was at $\mathrm{x} / \mathrm{c}=0.2$ and reattachment was at $\mathrm{x} / \mathrm{c}=0.6$, whereas separation and reattachment points for NACA 4412 were observed at $\mathrm{x} / \mathrm{c}=0.3$ and $\mathrm{x} / \mathrm{c}=0.5$, respectively. It remarked that variation of both thickness and camber ratio of airfoil caused the LSB length to reduce at $50 \%$, revealing the increment of aerodynamic performance.

It was clearly indicated from mentioned results that effects of variation of thickness and camber ratio on flow phenomena forming over the airfoils were obtained. Regarding contribution of admirable knowledge to aerodynamic researchers interested in numerical and experimental studies, this work will be useful in terms of comparison with their future work.

\section{CONCLUSION}

In this study, it was investigated how camber ratio and thickness of different airfoils affected their aerodynamic performance and LSB formation over suction surface of different airfoils. Results from numerical and experimental investigations were achieved as follows:

Concerning results of NACA 4412 and NACA 4415 airfoils, formation of the LSB was obviously changed when thickness of airfoil increased. It was clearly concluded that bubble size reduced with thicker airfoil. Furthermore, transition onset as well as the LSB formation was changed.

It was also revealed that aerodynamic phenomena over both NACA 2415 and NACA 4415 airfoils were affected in conjunction with increment of camber ratio. Result indicated that length of the LSB was reduced at $70 \%$. 
Apart from the LSB formation, results showed that cambered airfoil caused the separation and reattachment points to be changed understandably.

By means of experimental results of NACA 2415 and NACA 4412 airfoils, it was concluded that changing of both camber ratio and thickness of airfoils caused the flow properties to be changed. Results pointed out that the LSB length was diminished at $50 \%$ by changing its formation. In addition to bubble formation, transition onset was changed with variation of both thickness and camber ratio of airfoils.

\section{NOMENCLATURE}

$\begin{array}{ll}\text { C } & \text { Chord length } \\ \mathrm{U}_{\infty} & \text { Potential flow } \\ \text { LSB } & \text { Laminar Separation Bubble } \\ \text { APG } & \text { Adverse Pressure Gradient } \\ \text { PIV } & \text { Particle Image Velocimetry } \\ \text { UAV } & \text { Unmanned Aerial Vehicle } \\ \text { MAV } & \text { Micro Air Vehicle } \\ \text { SST } & \text { Shear Stress Transport } \\ \mathrm{C}_{\mathrm{L}} & \text { Lift Coefficient } \\ \tau & \text { Wall shear stress } \\ \mathrm{E} & \text { Voltage value coming from hot-film sensor } \\ \mathrm{E}_{0} & \text { Voltage at zero flow condition } \\ \mathrm{Lt}_{t} & \text { Transition length } \\ \alpha & \text { Angle of Attack } \\ \mathrm{Tu}_{\mathrm{u}} & \text { Turbulence Intensity } \\ \mathrm{X}_{\mathrm{t}} & \text { Transition Point } \\ \mathrm{X}_{\mathrm{s}}, \mathrm{S} & \text { Separation Point } \\ \mathrm{X}_{\mathrm{r}}, \mathrm{R} & \text { Reattachment Point } \\ \mathrm{Lb} & \text { Length of Laminar Separation Bubble }\end{array}$

\section{REFERENCES}

[1] Arcara P.C., Bartlett D.W., McCullers L.A. Analysis for the application of hybrid laminar flow control to a long-range subsonic transport aircraft. SAE Technical 1991; Paper No. 912113

[2] Carmichael B.H. Low Reynolds number airfoil survey, 1981, volume 1

[3] Mueller T.J., DeLaurier J.D. Aerodynamics of small vehicles. Annu. Rev. Fluid Mech. 2003; 35(1): 89-111.

[4] Hu H., Yang Z. An experimental study of the laminar flow separation on a low-Reynolds-number airfoil. J Fluid Eng 2008; 130(5): 051101.

[5] Gaster M. The structure and behaviour of laminar separation bubbles. HM Stationery Office 1969.

[6] Tani I. Low-speed flows involving bubble separations. Prog. Aerosp. Sci. 1964; 5: 70-103.

[7] Dovgal A.V., Kozlov V.V., Michalke A. Laminar boundary layer separation: instability and associated phenomena. Prog. Aerosp. Sci. 1994; 30(1): 61-94.

[8] Diwan S.S., Ramesh O.N. On the origin of the inflectional instability of a laminar separation bubble. J Fluid Mech. 2009; 629: 263-298.

[9] Brinkerhoff J.R., Yaras M.I. Interaction of viscous and inviscid instability modes in separation-bubble transition. Phys. Fluids 2011; 23(12): 124102.

[10] Cherry N.J., R. Hillier, Latour M.E.M. Unsteady measurements in a separated and reattaching flow. J Fluid Mech. 1984; 144(1): 13

[11] Hain R., Kähler C.J., Radespiel R. Dynamics of laminar separation bubbles at low-Reynolds-number aerofoils. J Fluid Mech. 2009; 630: 129-153.

[12] McAuliffe B.R., Yaras M.I. Separation-bubble-transition measurements on a low-Re airfoil using particle image velocimetry. ASME, 2005; Paper No. GT2005-68663.

[13] Burgmann S., Schröder W. Investigation of the vortex induced unsteadiness of a separation bubble via 
time-resolved and scanning PIV measurements. Exp. Fluids 2008; 45(4): 675.

[14] Genç, M.S., Kaynak, Ü., Yapıcı, H. Performance of transition model for predicting low Re aerofoil flows without/with single and simultaneous blowing and suction. Eur. J. Mech. (B/Fluids) 2011; 30(2): 218-235.

[15] Genç, M.S. Numerical simulation of flow over a thin aerofoil at a high Reynolds number using a transition model. Proceedings of the Institution of Mechanical Engineers, Part C: J. Mech. Eng. Sci. 2010; 224(10): 2155-2164.

[16] Genç, M.S., Kaynak, Ü., Lock, G.D. Flow over an aerofoil without and with a leading-edge slat at a transitional Reynolds number. Proceedings of the Institution of Mechanical Engineers, Part G: J. Aerosp. Eng. 2009; 223(3): 217-231.

[17] Genc, M., Lock, G., Kaynak, U. An experimental and computational study of low Re number transitional flows over an aerofoil with leading edge slat. In The 26th Cong. of ICAS and 8th AIAA ATIO, 2008 ; p. 8877.

[18] Genc, M.S., Koca, K., Açikel, H. H. Investigation of pre-stall flow control on wind turbine blade airfoil using roughness element. Energy 2019; 176: 320-334.

[19] Alpman, E. Aerodynamic performance of small-scale horizontal axis wind turbines under two different extreme wind conditions. J.Therm. Eng. 2015; 1(3): 420-432.

[20] Mahmoud, H. Stability of Turbine Blades, Aircraft Wings and Their Acoustic Radiation. J.Therm. Eng., 2015; $1: 6$

[21] Kaboglu, C. The effect of different types of core material on the flexural behavior of sandwich composites for wind turbine blades. J. Therm. Eng. 2017; 3(2): 1102-1109.

[22] Celik, A., Javani, N. Wind turbine blade flapwise and edgewise bending vibration analyses using energy methods. J. Therm. Eng. 2016, 2(6): 983-989.

[23] Genç, M.S., Koca, K., Demir, H., Açıkel, H.H. Traditional and New Types of Passive Flow Control Techniques to Pave the Way for High Maneuverability and Low Structural Weight for UAVs and MAVs. In: Unmanned Aerial Vehicles. IntechOpen, 2020.

[24] Cherrared, D. Numerical simulation of film cooling a turbine blade through a row holes. J. Therm. Eng., 2017; 3(2): 1110-1120.

[25] Bodur, T.M., Genç, M.S., Koca, K. Elimination of tip vortex using air holes at wind turbine blade. In: International Symposium on Sustainable Aviation. 2015.

[26] Maheri, A. Simulation of wind turbines utilizing smart blades. J. Therm. Eng. 2016; 2(1): 557-565.

[27] Karasu, İ., Özden, M., Genç, M.S. Performance Assessment of Transition Models for 3D Flow over NACA4412 Wings at Low Reynolds Numbers. J Fluid Eng Trans ASME 2018; 140: 12

[28] Koca K. The flow control with roughness devices over wind turbine airfoil, MSc. Thesis 2016 Graduate School of Natural and Applied Sciences. Turkey: Erciyes University, Kayseri,.

[29] Genç M.S., Koca K., Açıkel H.H., Ozkan G, Kırıs, MS, Yıldız R. Flow characteristics over NACA 4412 airfoil at low Reynolds number. In: EPJ web of conf. 2016, Vol. 114. EDP sciences,

[30] Poels A., Rudmin D., Benaissa A. Poirel D., Localization of flow separation and transition over a pitching NACA0012 airfoil at transitional Reynolds numbers using hot-films. J Fluid Eng. 2015; 137(12): 124501.

[31] Haghiri A.A., Mani M., Fallahpour N. Unsteady boundary layer measurement on an oscillating (pitching) supercritical airfoil in compressible flow using multiple hot-film sensors. Proceedings of the Institution of Mechanical Engineers, Part G: Journal of Aerosp. Eng. 2015; 229(10): 1771-1784.

[32] Bruun H.H., Hot-wire anemometry-principles and signal analysis, 1995.

[33] Hodson H.P., Howell R.J. Unsteady flow: its role in the low-pressure turbine. Minnow brook III, Workshop on

Boundary Layer Transition in Turbomachines 2000, Syracuse University

[34] Zhang X.F., Mahallati A., Sjolander S.A. Hot-film measurements of boundary layer transition, separation and reattachment on a low-pressure turbine airfoil at low Reynolds numbers. AIAA P. 2002; 36: 2002.

[35] Koca, K., Genç, M.S., Açikel, H.H., Çağdaş, M., Bodur, T.M. Identification of Flow Phenomena over NACA 4412 Wind Turbine Airfoil at Low Reynolds Numbers and Role of Laminar Separation Bubble on Flow Evolution. Energy 2017; 144: 750-764

[36] Genç M.S., Karasu I., Açıkel H.H. An experimental study on aerodynamics of NACA 2415 aerofoil at low Re numbers. Exp. Therm. Fluid Sci. 2012; 39: 252-264.

[37] Karasu I. Experimental and numerical investigations of transition to turbulence and laminar separation bubble over aerofoil at low Reynolds number flows, MSc. Thesis 2011, Graduate School of Natural and Applied Sciences, Erciyes University, Kayseri, Turkey. 